\title{
Gastric balloon causing small bowel obstruction: treatment by double-balloon enteroscopy
}

A 32-year-old woman was referred to our emergency department because of abdominal pain and vomiting. She had received a gastric balloon in an outpatient clinic 5 years previously to treat obesity, but had not attended follow-up appointments. Emergency computed tomography showed a partially deflated gastric balloon ( Fig. 1, arrow) in the mid part of the jejunum with proximal dilatation of the small bowel loops consistent with ileus.

To remove the gastric balloon from the jejunum, the patient was offered peroral double-balloon enteroscopy under conscious sedation. The gastric balloon was found at an insertion depth of $180 \mathrm{~cm}$ ( $\bullet$ Fig. 2a). To empty the methylene-bluecontaining saline out of the gastric balloon, a standard injection needle was used to perforate the silicone wall ( $\bullet$ Fig. 2 b). The deflated gastric balloon was folded up using a large polypectomy snare and was removed ( Fig. $\mathbf{2 c}$ ). The symptoms resolved quickly and the patient was discharged the next day.

Insertion of gastric balloons is performed as a temporary measure for weight loss [1]. If a gastric balloon remains longer than scheduled, it may deflate spontaneously and cause obstruction by entering the bowel. Similar cases have been treated by surgery [2-5]. However, double-balloon enteroscopy seems a promising method to treat bowel obstruction caused by partially deflated gastric balloons.

\section{Endoscopy_UCTN_Code_CPL_1AH_2AK}

Competing interests: None

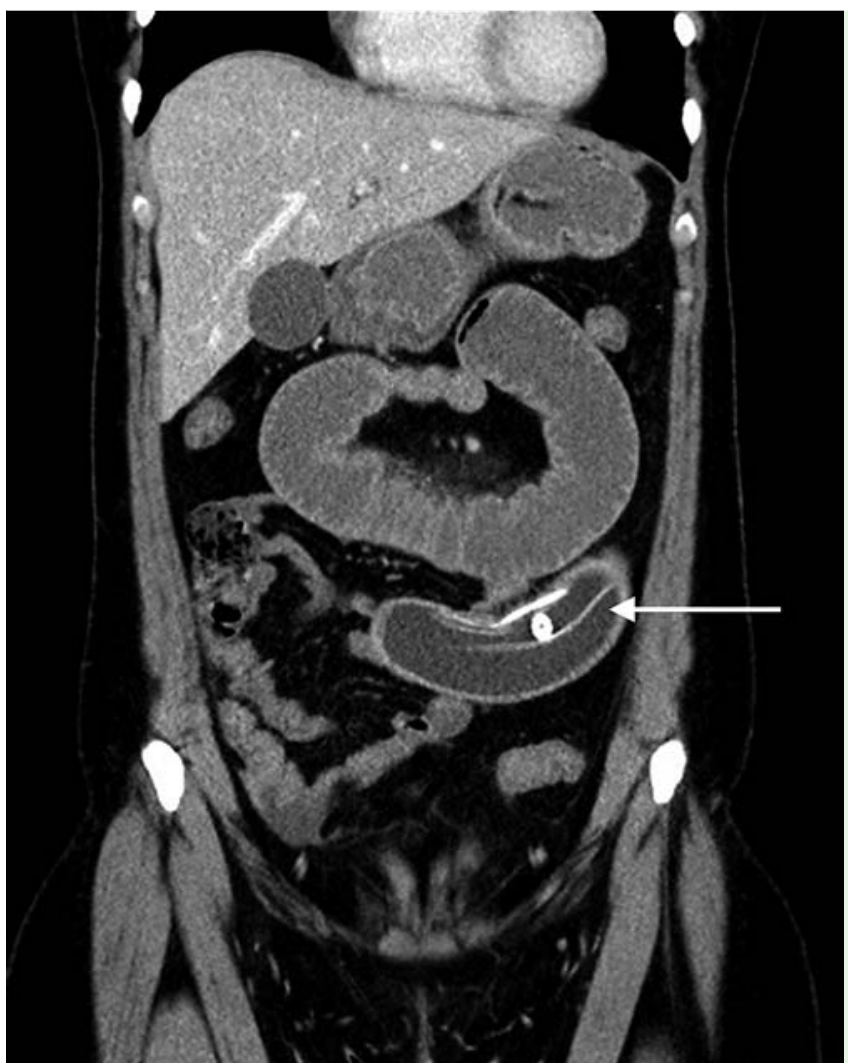

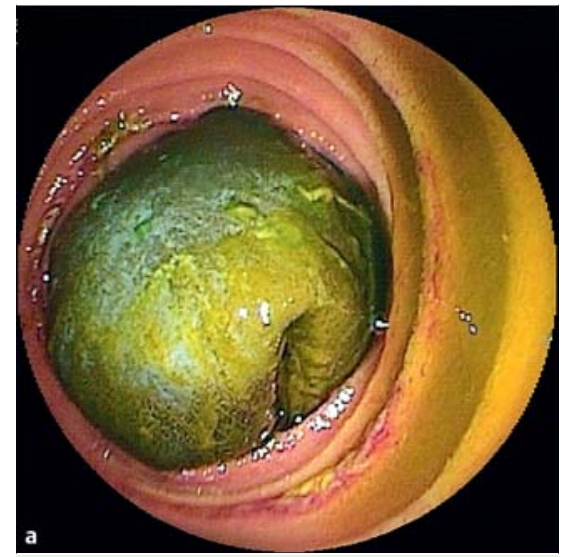
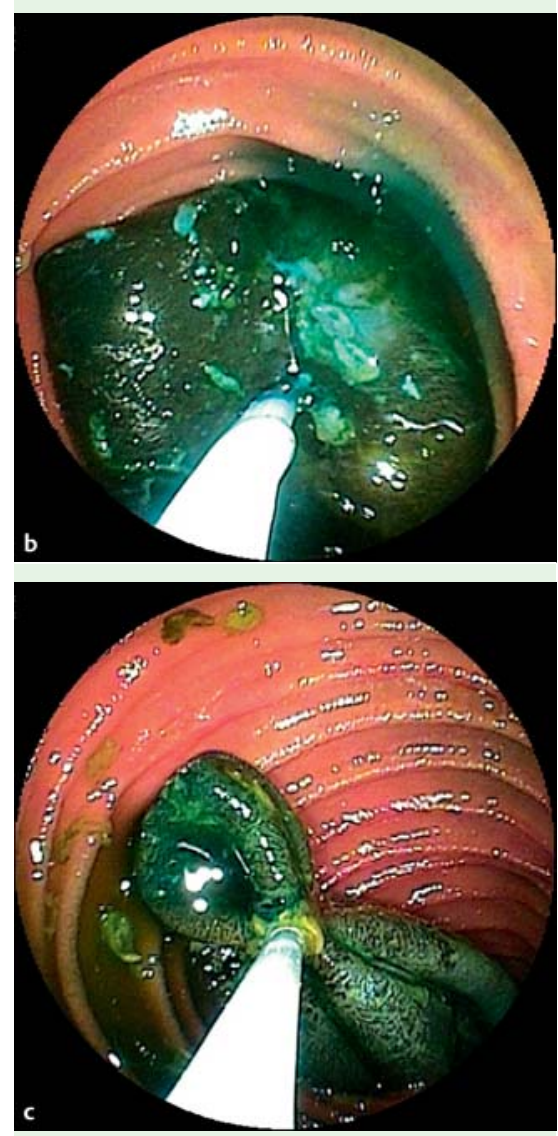

Fig. 2 a-c Removal of the gastric balloon by double-balloon enteroscopy: a gastric balloon in the mid part of the jejunum accompanied by superficial ulcerations; $\mathbf{b}$ perforation of the silicone wall with an injection needle; $c$ removal of the gastric balloon with a polypectomy snare. 


\section{U. Halm, M. Grothoff, R. Lamberts}

Park-Krankenhaus Leipzig, Klinik für Innere Medizin II, Leipzig, Germany

\section{References}

1 Dumonceau JM. Evidence-based review of the Bioenterics intragastric balloon for weight loss. Obes Surg 2008; 18: 1611 1617

2 Kim WY, Kirkpatrick UJ, Moody AP et al. Large bowel impaction by the BioEnterics intragastric balloon (BIB) necessitating surgical intervention. Ann R Coll Surg Engl 2000; 82: 202-204
3 Henninger $C$, Kramer $M$, Horger $M$ et al. Ileus of uncommon cause - important and weighty facts. Dtsch Med Wochenschr 2009; 134 : 2640

4 Hegade VS, Sood R, Douds AC. Small bowel obstruction induced by spontaneous partial deflation of an intragastric balloon. Ann R Coll Surg Engl 2012; 94: e171 -e173

5 Moszkowicz D, Lefevre JH. Deflated intragastric balloon-induced small bowel obstruction. Clin Res Hepatol Gastroenterol 2012; 36: e17-e19

\section{Bibliography}

DOI http://dx.doi.org/

10.1055/s-0032-1326265

Endoscopy 2013; 45: E78-E79

(c) Georg Thieme Verlag KG

Stuttgart · New York

ISSN 0013-726X

\section{Corresponding author}

\section{U. Halm, MD}

Park-Krankenhaus Leipzig

Strümpellstr. 41

04289 Leipzig

Germany

Fax: +49-341-8642264

ulrich.halm@parkkrankenhaus-leipzig.de 